\title{
Efficiency Optimization by Considering the High Voltage Flyback Transformer Parasitics using an Automatic Winding Layout Technique
}

Thummala, Prasanth; Schneider, Henrik; Zhang, Zhe; Ouyang, Ziwei; Knott, Arnold; Andersen, Michael A. E.

Published in:

IEEE Transactions on Power Electronics

Link to article, DOI:

10.1109/TPEL.2014.2379439

Publication date:

2015

Link back to DTU Orbit

Citation (APA):

Thummala, P., Schneider, H., Zhang, Z., Ouyang, Z., Knott, A., \& Andersen, M. A. E. (2015). Efficiency Optimization by Considering the High Voltage Flyback Transformer Parasitics using an Automatic Winding Layout Technique. IEEE Transactions on Power Electronics, 30(10), 5755 - 5768.

https://doi.org/10.1109/TPEL.2014.2379439

\section{General rights}

Copyright and moral rights for the publications made accessible in the public portal are retained by the authors and/or other copyright owners and it is a condition of accessing publications that users recognise and abide by the legal requirements associated with these rights.

- Users may download and print one copy of any publication from the public portal for the purpose of private study or research.

- You may not further distribute the material or use it for any profit-making activity or commercial gain

- You may freely distribute the URL identifying the publication in the public portal 


\title{
Efficiency Optimization by Considering the High Voltage Flyback Transformer Parasitics using an Automatic Winding Layout Technique
}

\author{
Prasanth Thummala ${ }^{*}$ Student Member IEEE, Henrik Schneider, Student Member IEEE, Zhe Zhang, \\ Member IEEE, Ziwei Ouyang, Member IEEE, Arnold Knott, Member IEEE, and Michael A. E. \\ Andersen, Member, IEEE
}

\begin{abstract}
This paper presents an efficiency optimization approach for a high voltage bidirectional flyback dc-dc converter. The main goal is to optimize the converter for driving a capacitive actuator, which must be charged and discharged from $0 \mathrm{~V}$ to $2.5 \mathrm{kV}$ dc and vice versa, supplied from a $24 \mathrm{~V} \mathrm{dc}$ supply. The energy efficiency is optimized using a proposed new automatic winding layout (AWL) technique and a comprehensive loss model. The AWL technique generates a large number of transformer winding layouts. The transformer parasitics such as dc resistance, leakage inductance and self-capacitance are calculated for each winding layout. An optimization technique is formulated to minimize the sum of energy losses during charge and discharge operations. The efficiency and energy loss distribution results from the optimization routine provide a deep insight into the high voltage transformer design and its impact on the total converter efficiency. The proposed efficiency optimization approach is experimentally verified on a $25 \mathrm{~W}$ (average charging power) with $100 \mathrm{~W}$ (peak power) flyback dc-dc prototype.
\end{abstract}

Index Terms - switched-mode power supply, high voltage dcdc power converter, transformer design, optimization, energy efficiency, actuators, dielectric films

\section{NOMENCLATURE}

$a_{u C}, b_{u C}$

Coefficients of Fourier series of the magneto motive force (MMF) during charge process (AT: Ampere-turns)

$B_{m C} / B_{m D} \quad$ Maximum flux density during charge / discharge process $(\mathrm{T})$

$B_{n C} \quad$ Magnitude of negative flux density at the beginning of a switching cycle during charge process $(\mathrm{T})$

$\Delta B$

Peak-to-peak flux density of the current excitation (T)

Manusctipt received on $8^{\text {th }}$ Sept. 2014, revised on $15^{\text {th }}$ Oct. 2014, and accepted on $24^{\text {th }}$ Nov. 2014. This paper has been presented at $29^{\text {th }}$ Annual Applied Power Electronics Conference, Fort Worth, TX, USA, March 2014.

All authors are with the Electronics Group, Department of Electrical Engineering, Technical University of Denmark, Kongens Lyngby, DK-2800 Denmark.

E-mail: " zo@elektro.dtu.dk, akn@elektro.dtu.dk,ma@elektro.dtu.dk.

"Indicates the corresponding author.

\begin{tabular}{|c|c|}
\hline$C_{\text {in }} / C_{\text {load }}$ & $\begin{array}{l}\text { Input capacitance / Capacitance of the load or } \\
\text { actuator }(\mathrm{F})\end{array}$ \\
\hline$C_{s}$ & Self-capacitance of secondary winding $(\mathrm{F})$ \\
\hline$C_{o s s p} / C_{o s s s}$ & $\begin{array}{l}\text { Output capacitance of low voltage MOSFET } M_{p} / \\
\text { high voltage MOSFET } M_{s}(\mathrm{~F})\end{array}$ \\
\hline$C_{D b}$ & Junction capacitance of high voltage diode $D_{b}(\mathrm{~F})$ \\
\hline$d_{p} / d_{s}$ & $\begin{array}{l}\text { Diameter of primary / secondary winding of } \\
\text { transformer }(\mathrm{mm})\end{array}$ \\
\hline$D_{2} / D_{b}$ & $\begin{array}{l}\text { High voltage }(5 \mathrm{kV}) \text { freewheeling diode } \\
\text { blocking diode }\end{array}$ \\
\hline$d_{\text {insulation }}$ & $\begin{array}{l}\text { Uniform spacing or thickness of the insulating } \\
\text { tape, between secondary layers }(\mathrm{mm})\end{array}$ \\
\hline$D_{o n C} / D_{o f f C}$ & $\begin{array}{l}\text { On-time / Off-time duty cycle of low voltage } \\
\text { MOSFET } M_{p} \text { during charge process }\end{array}$ \\
\hline$D_{o n D} / D_{o f f D}$ & $\begin{array}{l}\text { On-time / Off-time duty cycle of high voltage } \\
\text { MOSFET } M_{s} \text { during discharge process }\end{array}$ \\
\hline$E_{\text {load }}\left(V_{\text {out }}\right)$ & $\begin{array}{l}\text { Stored energy in the load at an output voltage } V_{\text {out }} \\
(\mathrm{J})\end{array}$ \\
\hline$f_{s w C} / f_{s w D}$ & $\begin{array}{l}\text { Switching frequency during charge / discharge } \\
\text { process }(\mathrm{kHz})\end{array}$ \\
\hline$F F_{L L}$ & $\begin{array}{l}\text { Fill factor of the last layer in the high voltage } \\
\text { winding }\end{array}$ \\
\hline$F_{u C}(0) / F_{u C}(h)$ & $\begin{array}{l}\text { MMF amplitude of } u^{\text {th }} \text { harmonic at } x=0 / x=h, h \text { is } \\
\text { the thickness of layer }\end{array}$ \\
\hline$G_{1}, G_{2}$ & $\begin{array}{l}\text { Constants used in the power loss expressions and } \\
\text { are functions of } \varepsilon_{u}\end{array}$ \\
\hline$H_{W}$ & Window height of transformer bobbin (mm) \\
\hline$i_{\text {in }} / i_{p} / i_{s}$ & $\begin{array}{l}\text { Input current / Primary current / Secondary or } \\
\text { load current (A) }\end{array}$ \\
\hline$i_{m p} / i_{m s}$ & Primary / Secondary magnetizing current (A) \\
\hline$I_{p p k C} / I_{p p k D}$ & $\begin{array}{l}\text { Primary peak current during charge process } \\
\text { discharge process }(\mathrm{A})\end{array}$ \\
\hline$I_{s p k C} / I_{s p k D}$ & $\begin{array}{l}\text { Secondary peak current during charge process / } \\
\text { discharge process }(\mathrm{A})\end{array}$ \\
\hline$i_{\min }$ & $\begin{array}{l}\text { Magnitude of the negative primary current at the } \\
\text { beginning of charge process (A) }\end{array}$ \\
\hline$I_{\text {pavgC }} / I_{\text {savgC }}$ & $\begin{array}{l}\text { Primary / Secondary average current during } \\
\text { charge process (A) }\end{array}$ \\
\hline$k_{z}$ & $\begin{array}{l}\text { Core loss constant in the improved generalized } \\
\text { Steinmetz equation ( } i \mathrm{GSE})\end{array}$ \\
\hline$L_{m p} / L_{m s}$ & $\begin{array}{l}\text { Primary / Secondary magnetizing inductance of } \\
\text { transformer }(\mathrm{H})\end{array}$ \\
\hline$L_{l k p} / L_{l k s}$ & $\begin{array}{l}\text { Leakage inductance referred to primary } \\
\text { secondary side of transformer }(\mathrm{H})\end{array}$ \\
\hline$M_{p} / M_{s}$ & $\begin{array}{l}\text { Low voltage MOSFET / High voltage }(4 \mathrm{kV}) \\
\text { MOSFET }\end{array}$ \\
\hline
\end{tabular}


TPEL-Reg-2014-09-1319

\begin{tabular}{|c|c|}
\hline$N_{p} / N_{s} / n$ & $\begin{array}{l}\text { Number of primary / secondary turns / Turns ratio } \\
\text { of transformer from secondary to primary }\end{array}$ \\
\hline$n_{l p} / n_{l s}$ & $\begin{array}{l}\text { Number of layers in primary / secondary winding } \\
\text { of transformer }\end{array}$ \\
\hline$n_{\text {parp }} / n_{\text {pars }}$ & $\begin{array}{l}\text { Number of parallel wires in primary / secondary } \\
\text { winding of transformer }\end{array}$ \\
\hline$N_{h} / N_{c}$ & $\begin{array}{l}\text { Total number of harmonics considered / Total } \\
\text { number of switching cycles during charge process }\end{array}$ \\
\hline$P_{\text {layerC }}^{k}$ & Power loss in $k^{\text {th }}$ layer during charge process $(\mathrm{W})$ \\
\hline$P_{\text {wind } C} / P_{T w i n d C}$ & $\begin{array}{l}\text { Winding loss at each switching cycle / Total } \\
\text { winding loss during charge process (W) }\end{array}$ \\
\hline$P_{s w C} / P_{s w D}$ & $\begin{array}{l}\text { Capacitive switching loss due the self-capacitance } \\
\text { during charge / discharge process (W) }\end{array}$ \\
\hline$P_{s n C} / P_{s n D}$ & $\begin{array}{l}\text { Snubber loss due leakage inductance during } \\
\text { charge / discharge process (W) }\end{array}$ \\
\hline$R_{p} / R_{s}$ & $\begin{array}{l}\text { dc resistance of primary / secondary winding of } \\
\text { transformer }(\Omega)\end{array}$ \\
\hline$R_{\text {psense }} / R_{\text {ssense }}$ & $\begin{array}{l}\text { Primary / Secondary current sense resistance }(\Omega) \\
\text { dc resistance of a given laver }(\Omega)\end{array}$ \\
\hline$t_{\text {onC }} / t_{\text {offC }}$ & $\begin{array}{l}\text { On-time / Off-time of low voltage MOSFET } M_{p} \\
\text { during charge process (s) }\end{array}$ \\
\hline$t_{\text {onD }} / t_{\text {offD }}$ & $\begin{array}{l}\text { On-time / Off-time of high voltage MOSFET } M_{s} \\
\text { during discharge process (s) }\end{array}$ \\
\hline$T_{s C} / T_{s D}$ & $\begin{array}{l}\text { Switching period during charge / discharge } \\
\text { process }(\mathrm{s})\end{array}$ \\
\hline$T_{c h}$ & $\begin{array}{l}\text { Charging time to reach the target output voltage } \\
\text { from } 0 \mathrm{~V}(\mathrm{~s})\end{array}$ \\
\hline$T_{\text {layer }}$ & $\begin{array}{l}\text { Number of turns in a given layer (primary or } \\
\text { secondary) of transformer }\end{array}$ \\
\hline$V_{\text {leakD }}$ & $\begin{array}{l}\text { Increase in the steady state drain-to-source } \\
\text { voltage of } M_{s} \text { due to leakage inductance } L_{l k s}(\mathrm{~V})\end{array}$ \\
\hline$V_{\text {in }} / V_{\text {out }}$ & $\begin{array}{l}\text { Input voltage / Output or load or actuator voltage } \\
\text { (V) }\end{array}$ \\
\hline$W_{W}$ & Window width of bobbin (mm) \\
\hline$W_{s q p} / W_{s q s}$ & $\begin{array}{l}\text { Width of square for primary / secondary in the } \\
\text { automatic winding layout generator routine ( } \mathrm{mm} \text { ) }\end{array}$ \\
\hline$\gamma_{s} / \gamma_{p}$ & $\begin{array}{l}\text { Height allocation factor for secondary / primary } \\
\text { winding with } \gamma_{p}=\left(1-\gamma_{s}\right)\end{array}$ \\
\hline$\delta_{u} / \delta$ & $\begin{array}{l}\text { Skin depth of the conductor at } u^{\text {th }} \text { harmonic } \\
\text { frequency / fundamental }(u=0) \text { frequency }(\mathrm{mm})\end{array}$ \\
\hline$\varepsilon_{u}$ & $\begin{array}{l}\text { Ratio of conductor diameter to the effective skin } \\
\text { depth of } u^{\text {th }} \text { harmonic }\end{array}$ \\
\hline$\varphi_{u C}(0) / \varphi_{u C}(h)$ & $\begin{array}{l}\text { Phase of } u^{\text {th }} \text { harmonic of the MMF during charge } \\
\text { process at } x=0 / x=h \text { ( } h \text { is thickness of layer) }\end{array}$ \\
\hline$\rho / \mu_{0}$ & $\begin{array}{l}\text { Resistivity of copper }(\Omega-m) \quad / \text { Magnetic } \\
\text { permeability of vacuum }(H / m)\end{array}$ \\
\hline$\alpha, \beta, k$ & $\begin{array}{l}\text { The constants related to core material which are } \\
\text { provided by the core manufacturer }\end{array}$ \\
\hline$\delta_{C}$ & Capacitance ratio factor on the high voltage side \\
\hline
\end{tabular}

\section{INTRODUCTION}

$\mathrm{D}$ IELETRC electro active polymer (DEAP) [1]-[3] is an evolving smart material that can be used in actuation, sensing and energy harvesting applications [4]. DEAPs, when used as linear actuators, have the potential to be an effective replacement for many conventional linear actuators because of their unique properties, including light weight, low noise operation, high flexibility, large strain, and autonomous capability. The axial DEAP actuator as shown in Fig. 1(a) is ideally equivalent to a capacitive load. When a DEAP actuator is driven with high voltage $(2-2.5 \mathrm{kV})$, it converts a portion of the electrical energy into mechanical displacement, which is of the order of $\mathrm{mm}(\sim 1-1.5 \mathrm{~mm})$ [5]-[7]. Three of such axial
DEAP actuators are used to create a DEAP incremental actuator [8] as shown in Fig. 1(b). The DEAP incremental actuator technology has the potential to be used in various industries, e.g. automotive, aeronautics, and medicine. For using the DEAP actuators in such applications, the high voltage drivers should have low volume to fit inside or above the actuators. The overall energy efficiency of battery powered, high voltage driver influences, the distance travelled by the incremental actuator. Hence, for DEAP actuator applications, both volume and energy efficiency of high voltage drivers are extremely important and need to be optimized.

The flyback converter is suitable for high voltage and low power applications due to its simple structure and a low component count [9]. High voltage switch-mode power supplies for charging the capacitive loads are implemented in [10]-[12]. Bidirectional dc-dc power converters are needed for the DEAP based capacitive actuators [13], to increase the lifetime of the battery, also to discharge the high voltage across them. Bidirectional flyback converter [14]-[17], and a forward-flyback bidirectional converter [18] are implemented for various applications. Due to high reverse recovery time $(\sim 2.6 \mu \mathrm{s})$ of high voltage MOSFET, a modified high voltage bidirectional flyback converter topology [19] as shown in Fig. 2 , is proposed and implemented for driving a DEAP actuator. The loss analysis of the same converter is performed in [20].

Transformer design plays a very important role in high voltage dc-dc power converters employed in low, medium and high power applications. The design methodologies for transformers used in conventional switch-mode power supplies are well documented [9], [21]-[23]. Often, a transformer for a given application is designed based on some assumptions such as, constant switching frequency, maximum

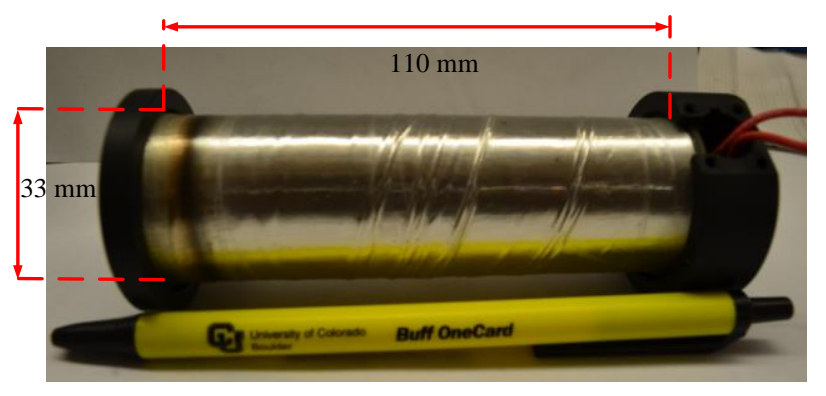

a)

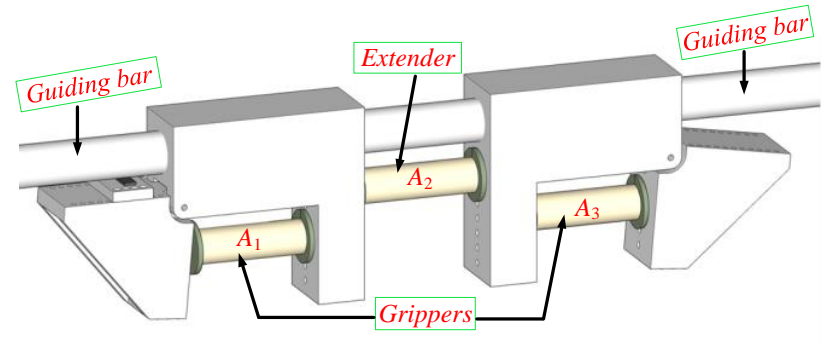

b)

Fig. 1. a) DEAP actuator; b) DEAP incremental actuator. 


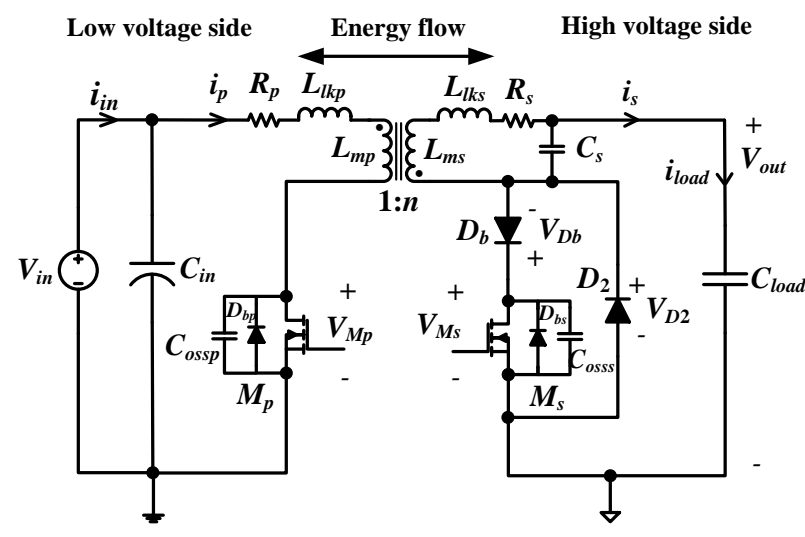

Fig. 2. Circuit configuration of the high voltage bidirectional flyback converter for driving a capacitive load.

temperature rise, estimated converter efficiency, winding fill factor, and winding current density. However, these assumptions are not valid or suitable for some applications. Hence, more customized procedures are needed to design efficient transformers, for specific applications. In a high voltage capacitor charge and discharge application, the high voltage transformer will have a large amount of (> 200) secondary turns. For such application, it is very difficult to select an optimum winding diameter and number of winding layers beforehand, which decide the values of the transformer parasitics. To avoid this difficulty, an automatic winding layout (AWL) technique is introduced in [24], for the winding design of a high voltage transformer. The high voltage flyback converter operation is very sensitive to the transformer parasitics. The proposed AWL technique, utilizes the entire available space in a given transformer bobbin and provides an optimum winding diameter that minimizes the total loss due to the transformer parasitics.

In the initial design phase, it is difficult to predict which core type is optimal for a given application. In a flyback converter, a long transformer window width is often preferred, in order to minimize the leakage inductance and ac resistance by providing a close coupling between windings, and to decrease the number of winding layers. For high output or input voltage flyback converters, this could be different, since the self-capacitance of the high voltage winding has significant impact on the performance of the converter. In this paper, an efficiency optimization algorithm is proposed, which provides an optimum solution for a given transformer core, by using the proposed AWL technique and the comprehensive loss model. Different transformer winding architectures (TWAs) for the high voltage capacitor charge and discharge application are investigated in [25]. In [26], a digital control technique is proposed for improving the energy efficiency and charge/discharge speed. Control algorithms for optimalflyback charging of a capacitive load are proposed in [27]. A number of switch-mode power supply design optimization methods have been described in the literature [28]-[34].

The proposed efficiency optimization technique has the following features:

1) an automatic winding layout (AWL) technique, which produces the

2) information about winding diameters, number of layers, and number of parallel windings, for both primary and secondary windings;

3) an accurate calculation of transformer parasitics using the outputs of AWL technique;

4) calculation of energy losses during charge and discharge modes using a comprehensive loss model;

5) an objective function that minimizes the sum of energy losses during charge and discharge modes, over a range of operating points.

This paper is organized as follows: Section II describes the proposed automated winding layout (AWL) technique. Section III provides the loss modeling of the bidirectional flyback converter. Section IV discusses the proposed optimization routine. Section $\mathrm{V}$ provides the optimization and experimental results, followed by the conclusions in Section VI.

\section{Automatic Winding Layout (AWL) Technique}

The bidirectional flyback converter design specifications are provided in Table I. The magnetic transformer is the most critical component in the high voltage bidirectional flyback converter. The leakage inductance causes voltage spikes across the drain-to-source of the MOSFET, and this can be avoided by a dissipative snubber circuit or by using an over rated MOSFET. The self-capacitance of the secondary winding creates large resonating current spikes in the leading edge of the MOSFET current waveform [19]. Additional switching losses will be created due to those two parasitics, respectively [30]. The remaining losses in the transformer are core loss, and the winding loss due to dc and ac resistances. The losses due to the high voltage transformer need to be minimized to improve the bidirectional flyback converter efficiency and reliability.

TABLE I

CONVERTER DESIGN SPECIFICATIONS

\begin{tabular}{c|c}
\hline \hline Parameter & Value \\
\hline \hline Input voltage $V_{\text {in }}$ & $24 \mathrm{~V}$ \\
\hline Output voltage $V_{\text {out }}$ & $0-2500 \mathrm{~V}$ \\
\hline Capacitance of load $C_{\text {load }}$ & $400 \mathrm{nF}$ \\
\hline $\begin{array}{c}\text { Stored energy in the load } E_{\text {load }} \\
\text { at } 2.5 \mathrm{kV}\end{array}$ & $1.25 \mathrm{~J}$ \\
\hline Target charging time $T_{\text {ch }}$ & $50 \mathrm{~ms}$ \\
\hline Turns ratio of the transformer $n$ & 25 \\
\hline $\begin{array}{c}\text { Primary magnetizing inductance } L_{m p} \\
\text { process } I_{p p k C}\end{array}$ & $44 \mu \mathrm{H}$ \\
\hline $\begin{array}{c}\text { Primary peak current during } \\
\text { discharge process } I_{p p k D}\end{array}$ & $4.2 \mathrm{~A}$ \\
\hline \hline
\end{tabular}

The transformer design decisions considered for the proposed AWL technique are given in Table II. The core types are limited to ETD, EFD, E, RM and PQ. The N87 core material is chosen for most of the cores, due to its lower core losses at high frequency up to $500 \mathrm{kHz}$. For those cores for 
which N87 material is not available, other core materials which are suitable for operation up to $500 \mathrm{kHz}$ are considered. A simple, non-interleaved winding structure (P/S; P: Primary, $\mathrm{S}$ : Secondary), is considered in this paper to limit the complexity of the proposed AWL technique. Nevertheless, the proposed AWL technique can be easily extended for the interleaved transformer structures $(\mathrm{P} / \mathrm{S} / \mathrm{P}$ or $\mathrm{S} / \mathrm{P} / \mathrm{S})$. The proper insulation between the low voltage (primary) and high voltage (secondary) windings is achieved by using a triple insulated (TEX-E) solid wire for primary winding. To avoid the high insulation thickness $(0.2 \mathrm{~mm})$ of TEX-E wire, single insulated solid wire is used for a large number of secondary turns. A maximum transformer temperature limit of $130{ }^{\circ} \mathrm{C}$ is chosen. These limitation values can be altered based on the experience of the user or the initial design specifications.

The AWL technique is described below:

\section{A. AWL technique:}

The space allocated for the primary and secondary windings for a given transformer bobbin with winding width $W_{W}$ and window height $H_{W}$ are shown in Fig. 3(a). Different steps associated with the proposed AWL technique for an example of $N_{p}=6$ primary turns and $N_{s}=18$ secondary turns, are explained below:

1) The first step is, to split the available winding space for primary (see Fig. 3(a)) and secondary (Fig. 3(f)) into a number of squares, with a square width equal to height allocated for that winding. As shown in Figs. 3(d) and $3(\mathrm{~g})$, it results into 4 squares and a crossed non-square, which is considered as an unusable space for both primary and secondary windings. In each square, a solid round wire could be placed with a diameter equal to the width of a square or a bundle of round wires with an outside bundle diameter equal to the width of a square.

2) Since the number of available squares is 4 in Figs. 3(d) or $3(\mathrm{~g})$, which is less than the required 6 primary and 18 secondary turns, more squares are required to fill the needed turns. Hence, the width of square for primary or secondary is decreased from its maximum value of $\gamma_{p} H_{W}$ or $\gamma_{s} H_{W}$, respectively.

3) The fill factor of the last layer $F F_{L L}$ for a given winding is defined as the ratio of the number of squares used in the final layer to the number of squares available in it. For example, in Fig. 3(i), 9 squares are available and 9 squares are occupied in the final layer, hence $F F_{L L}=1$. Similarly, in Fig. 3(j), 16 squares are available and 13 squares are occupied in the final layer, hence $F F_{L L}=0.81$. In the proposed AWL technique a maximum limit of 0.85 is set for $F F_{L L}$, since the calculation of transformer parasitics is based on fully occupied layers.

4) When the square width is reduced as shown in Figs. 3(e) and 3(h), the new square size limits the use of a shaded space above the squares. For primary winding since only 6 turns are needed, this will be a valid solution. However, for secondary winding, since 18 turns are needed, the shaded space can be occupied by the other windings, by reducing the square width further.

5) When the square width is reduced further as shown in Fig. 3 (i), the winding space contains 18 squares in 2 layers, and a shaded space. The non-square horizontal space is utilized to provide an insulation tape (with thickness $\left.d_{\text {insulation }}\right)$ between the secondary layers. This is the final step of the AWL technique for 6 primary and 18 secondary turns.

6) If 45 turns are required for the secondary winding, the square width is decreased again, as shown in Fig. 3(j), the solution contains 3 layers and 16 squares in each layer. The last layer fill factor $F F_{L L}$ in this case is 0.81 , which is less than 0.85 . Hence, this is not a valid solution and the square width needs to be decreased further.

7) In Fig. 3(b), a solution from the AWL technique is shown. The primary and secondary squares are filled with triple isolated and single isolated solid wires, respectively. The same steps described above apply for the real high voltage transformer design which will have more than 200 secondary turns.

8) Finally, the outputs of AWL technique are various winding implementations, including specific winding details such as, diameters of primary and secondary windings, number of primary and secondary winding layers, and insulation thicknesses for placing between secondary windings, for which $F F_{L L}>0.85$, respectively.

TABLE II

TRANSFORMER DESIGN DECISIONS

\begin{tabular}{c|c|c}
\hline \hline Description & Design decision & Comments \\
\hline \hline Ferrite core and bobbin type & ETD, EFD, E, RM and PQ & Typically used in switch-mode power supplies. \\
\hline Core material & N87 & Suitable for switching frequencies up to 500 kHz. \\
\hline Winding structure & P/S & Simple implementation and decreases analytical complexity. \\
\hline Primary winding type & Solid wire & Flexible winding type in terms of design and prototyping. \\
\hline Primary winding insulation & Triple insulation (TEX-E) & $\begin{array}{c}\text { Edge tape can be avoided. No need for interlayer insulation tape between the } \\
\text { primary and secondary windings. }\end{array}$ \\
\hline $\begin{array}{c}\text { Secondary winding type } \\
\text { Secondary winding } \\
\text { insulation }\end{array}$ & Solid wire & $\begin{array}{c}\text { Suitable winding type, for a large number of turns. Flexible winding type in terms } \\
\text { of design, prototyping and different winding structures. }\end{array}$ \\
\hline Air gap & Single insulation & Provides minimum insulation thickness for a large number of turns. \\
temperature & All legs & Simplifies the prototyping. \\
\hline $\begin{array}{c}\text { Maximum transformer } \\
\text { temperature rise of } 95^{\circ} \mathrm{C} .\end{array}$ \\
\hline \hline
\end{tabular}


TPEL-Reg-2014-09-1319

Top view of the bobbin for horizontal E and ETD, EFD cores Side view of the bobbin for verticle $\mathrm{E}$ cores and $\mathrm{PQ}, \mathrm{RM}$ cores

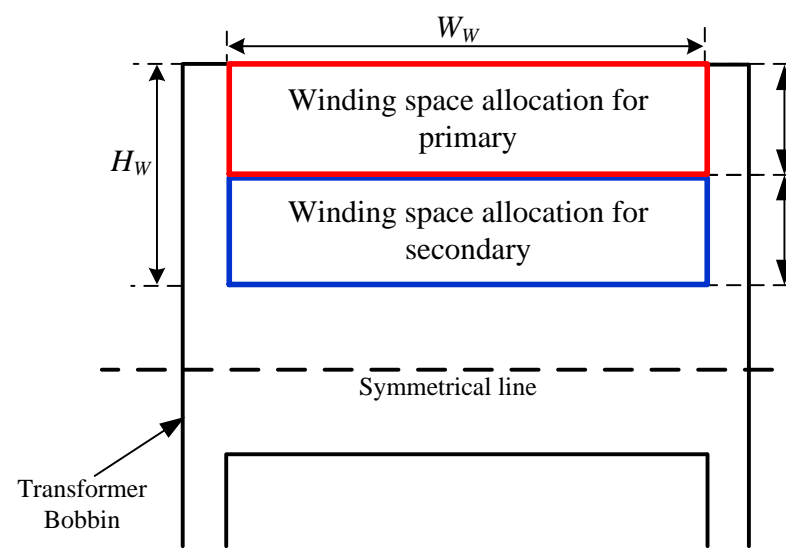

a)

c)

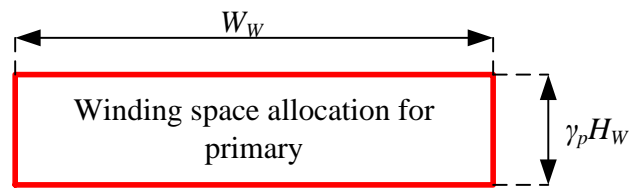

d)

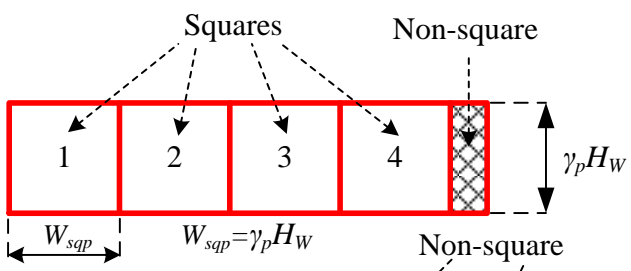

e)

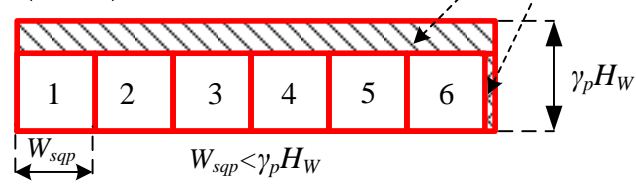

Crossed space which is not utilized by the windings

Space equally distributed between secondary layers

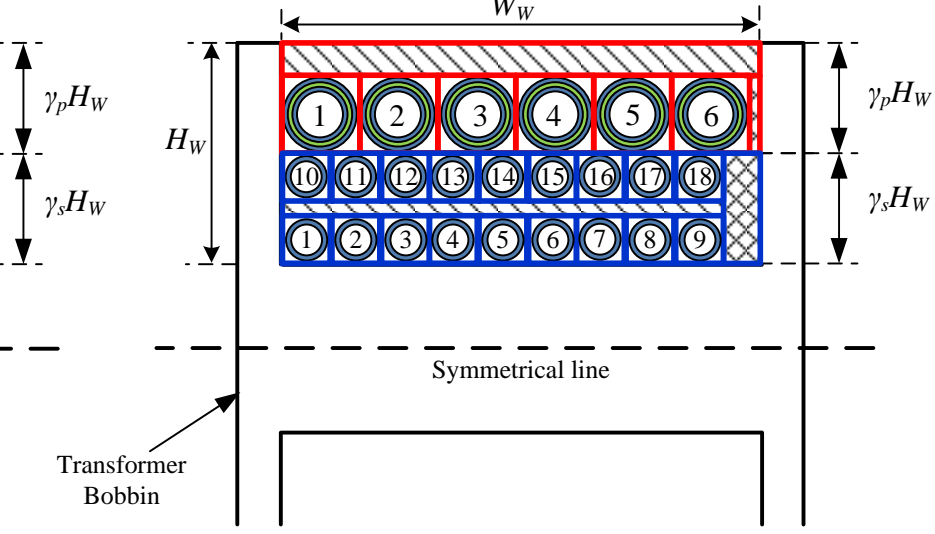

b) i)

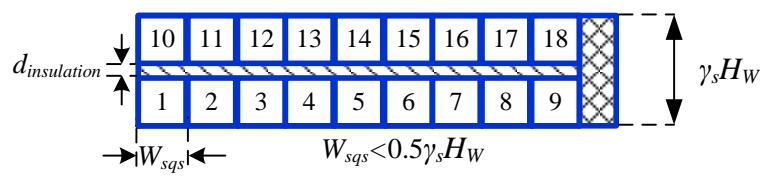

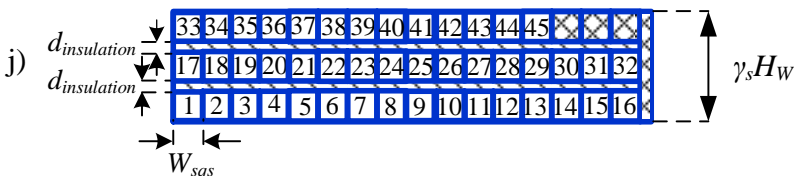

Fig. 3. a) Allocated winding space a) before applying AWL technique; b) after applying AWL technique; c) - e) Different steps involved in AWL technique for primary winding; f) - j) Different steps involved in AWL technique for secondary winding;

B. Calculation of transformer parasitics using the results of AWL technique:

The outputs of the AWL technique are used to calculate the transformer parasitics [20], [24], [35]-[37] such as dc resistance, leakage inductance and self-capacitance. In Fig. 4, one output of AWL technique such as the insulation thickness $\left(d_{\text {insulation }}\right)$ for a PQ $20 / 20$ core, and calculated transformer parasitics are shown with respect to square width $\left(W_{s q s}\right)$ of secondary winding. As the width of the secondary square (or secondary winding) decreases, the insulation spacing $d_{\text {insulation }}$ between secondary winding layers increases, dc resistance $R_{s}$ increases, leakage inductance $L_{l k p}$ slightly decreases, and the self-capacitance $C_{s}$ decreases.
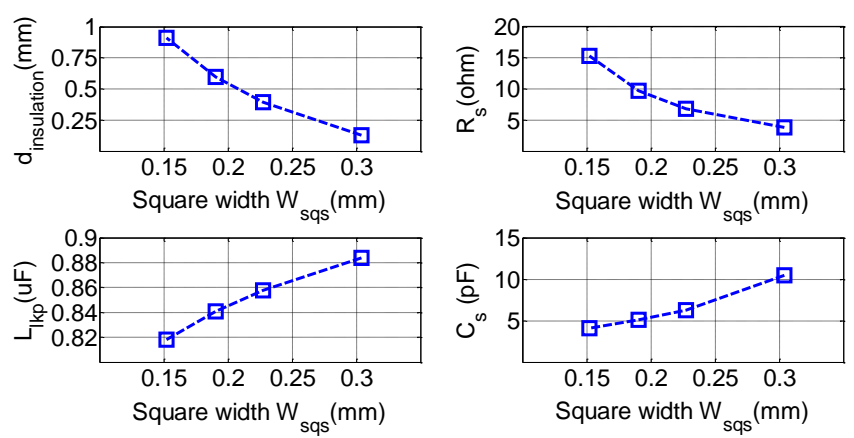

Fig. 4. Variation of transformer parasitics with the diameter of secondary winding, for PQ $20 / 20$ core (when $\gamma_{s}=0.8$ ). 
TPEL-Reg-2014-09-1319

\section{LOSS MODELLING}

In order to investigate the bidirectional flyback converter efficiency, it is necessary to calculate the losses associated with each circuit component in the converter. The loss model is a function of transformer parasitics. Different losses in the bidirectional flyback converter are given below:

\section{A. Transformer winding loss:}

In a flyback converter the primary and secondary currents are $180^{\circ}$ out of phase, hence the conventional equations cannot be used to calculate the ac resistance [38], [39]. The calculation of the total winding loss in a flyback converter using the magneto motive force (MMF) analysis [40], [41] is described below.

1) Winding loss in a flyback transformer during charge process:

For the winding loss modeling, a non-interleaved transformer with 2 layers on the primary side $\left(P_{1}\right.$ and $\left.P_{2}\right)$ and 5 layers on the secondary side $\left(S_{1}, S_{2}, S_{3}, S_{4}\right.$ and $\left.S_{5}\right)$, is considered as an example. The MMF distribution in a flyback transformer is different from that of a normal transformer [40]. Figure 5 shows different MMF distributions during both turnon $\left(0<t<t_{\text {onC }}\right)$ and turn-off $\left(t_{o n C}<t<t_{o n C}+t_{o f f C}\right)$ periods in a noninterleaved flyback transformer. In Fig. 5, $N_{p 1}$ and $N_{p}$, are the number of turns in the primary layer 1 and the total primary turns, respectively, and $H_{0}, H_{1}, \ldots . H_{7}$ are the magnetic field intensities between the layers. The terms $N_{1}, N_{2}, N_{3}, N_{4}, N_{5}$ are defined as follows: $N_{1}=N_{s 1}, \quad N_{2}=N_{s 1}+N_{s 2}, N_{3}=N_{s 1}+N_{s 2}+N_{s 3}$, $N_{4}=N_{s 1}+N_{s 2}+N_{s 3}+N_{s 4}$, and $N_{5}=N_{s 1}+N_{s 2}+N_{s 3}+N_{s 4}+N_{s 5}=N_{s}$ where $N_{s 1}, N_{s 2}, N_{s 3}, N_{s 4}, N_{s 5}$ and $N_{s}$ are the number of turns in the secondary layers $1,2,3,4,5$, and the total number of secondary turns, respectively. The primary $i_{m p}(t)$ and secondary $i_{m s}(t)$ magnetizing current waveforms in a given switching cycle, during charge and discharge processes are shown in Figs. 6(a) and 6(b), respectively. The MMF distribution in each transformer winding layer in the time

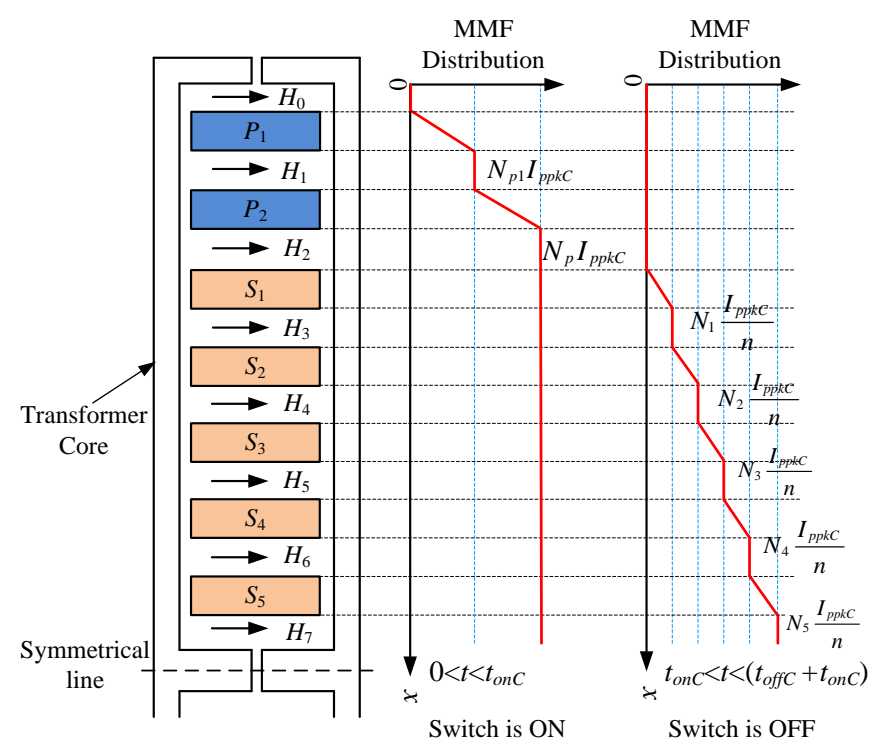

Fig. 5. MMF distribution of the non-interleaved (P-P-S-S-S-S-S) flyback transformer with respect to space.

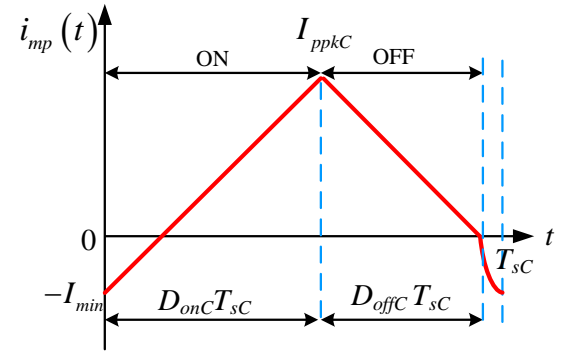

a)

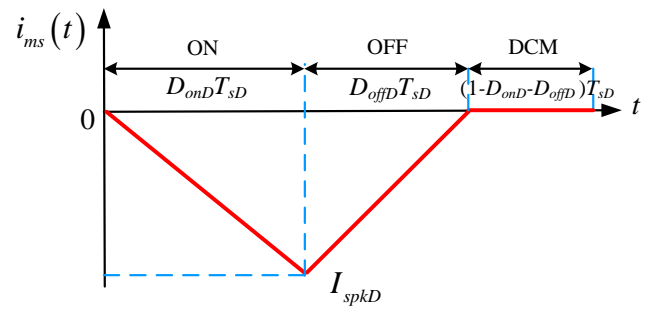

b)

Fig. 6. a) Primary magnetizing current in a given switching cycle during charge process, and b) Secondary magnetizing current discharge process.

domain is decomposed into sinusoidal harmonics by Fourier series analysis [24]. The power loss is then computed for each harmonic, and the power loss densities over all harmonics are summed to find the power dissipated in each layer.

The power loss expression in $k^{\text {th }}$ layer $P_{\text {layer }}^{k}$ is given by [24],

[40], [41]

$$
\begin{aligned}
P_{\text {layer } C}^{k}=\frac{R_{\text {layer }}}{2 T_{\text {layer }}^{2}} \sum_{u=1}^{N_{h}} \varepsilon_{u}\left[\begin{array}{l}
\left(\left|F_{u C}(h)\right|^{2}+\left|F_{u C}(0)\right|^{2}\right) G_{1}\left(\varepsilon_{u}\right)- \\
4\left|F_{u C}(h)\right|\left|F_{u C}(0)\right| \cos (\Delta \varphi) G_{2}\left(\varepsilon_{u}\right)
\end{array}\right] \\
\delta_{u}=\sqrt{\frac{\rho}{\pi \mu_{0} u f_{s w C}}} \\
\varepsilon_{u}=\left(\frac{\pi}{4}\right)^{0.75} \sqrt{\frac{T_{\text {layer }}}{W_{W}}}\left(\frac{d^{1.5}}{\delta_{u}}\right)
\end{aligned}
$$

where $F_{u C}(0)$ and $F_{u C}(h)$ are the MMF amplitudes of the $u^{\text {th }}$ harmonic at the beginning $(x=0)$ and end $(x=h)$ of a layer, respectively, $d$ is the diameter of the given winding, $h$ is the thickness of a given layer, with the suffix $u$ being the harmonic number [24].

The magnitude $\left|F_{u C}\right|$ and phase $\varphi_{u C}$ of $u^{\text {th }}$ harmonic of the MMF during charge process are given by

$$
\begin{gathered}
\left|F_{u C}\right|=\sqrt{a_{u C}^{2}+b_{u C}^{2}} \\
\varphi_{u C}=\left\{\begin{array}{l}
\tan ^{-1}\left(-\frac{b_{u C}}{a_{u C}}\right), \text { if } a_{u C} \geq 0 \\
\pi+\tan ^{-1}\left(-\frac{b_{u C}}{a_{u C}}\right), \text { if } a_{u C}<0
\end{array}\right. \\
\Delta \varphi=\varphi_{u C}(0)-\varphi_{u C}(h)
\end{gathered}
$$

where $a_{u C}$ and $b_{u C}$ are the coefficients of the Fourier series of the MMF during charge process and are provided in [24], and $\Delta \varphi$ is the difference between the phase angles of the $u^{\text {th }}$ 
harmonic at the beginning $(x=0)$ and end $(x=h)$ of a layer, respectively.

The expression for the winding loss in a flyback transformer at each switching frequency (each switching cycle) index $j$ during charge process is

$$
P_{\text {windC }}(j)=I_{\text {pargC }}^{2}(j) R_{p}+I_{\text {sarg }}^{2}(j) R_{s}+\sum_{k=1}^{n_{s}+n_{l_{p}}} P_{\text {layerC }}^{k}(j)
$$

The total winding loss during charge process having $N_{c}$ switching cycles is

$$
P_{T \text { windC }}=\sum_{j=1}^{N_{c}} P_{\text {wind } C}(j)
$$

\section{2) Discussion:}

The winding loss during discharge process is calculated similar to that during charge process. The AC loss due to airgap fringing field [28] has not been considered because of difficulties in interfacing the 2-D/3-D finite element analysis (FEA) simulation results with the optimization process. The negative current at the beginning of the turn-on process during charge process in Fig. 6(a) is due to the high voltage winding self-capacitance. When the secondary winding current becomes zero, the drain to source voltage $V_{M p}$ tends to decrease. Since the control IC, LT3751 [42] operates under boundary mode control, the next switching cycle starts before the high voltage winding capacitance completely discharges. Hence, the current flows in the reverse direction to discharge the high voltage winding capacitance.

\section{B. Transformer core loss:}

The time-average core loss per unit volume $P_{v}$ due to nonsinusoidal excitation is calculated using the improved generalized Steinmetz equation ( $i \mathrm{GSE})$ [43] which is given by

$$
P_{v}=\frac{1}{T_{s}}\left[\int_{0}^{T_{s}} k_{z}\left|\frac{d B(t)}{d t}\right|^{\alpha}(\Delta B)^{\beta-\alpha} d t\right]
$$

where $\left|\frac{d B(t)}{d t}\right|$ is the absolute value of the change rate of the flux density, $\Delta B$ is the peak-to-peak flux density, $T_{s}$ is the switching period, and $k, \alpha$ and $\beta$ are the constants provided by the core manufacturer. The core loss coefficient $k_{z}$ in (9) is calculated using the following expression

$$
k_{z}=\frac{k}{(2 \pi)^{\alpha-1} 2^{\beta-\alpha}\left[\int_{0}^{2 \pi}|\cos \theta|^{\alpha} \mathrm{d} \theta\right]}
$$

The angle $\theta$ in (10) represents the phase angle of the sinusoidal excitation. For a given values of $k, \alpha$ and $\beta$, the value of coefficient $k_{z}$ in (10) is fixed, irrespective of shape of the flux density waveform.

The core loss per unit volume using $i \mathrm{GSE}$ during charge operation (where $\Delta B=B_{m C}+B_{n C}$ during the turn-on period and $\Delta B=B_{m C}$ during the turn-off period), in each switching cycle is given by

$$
P_{v C}=\frac{k_{z}}{T_{s C}}\left[\left(B_{m C}+B_{n C}\right)^{\beta} \cdot t_{o n C}^{1-\alpha}+B_{m C}^{\beta} \cdot t_{o f f C}^{1-\alpha}\right]
$$

Similarly, the core loss per unit volume during discharge operation (where $\Delta B=B_{m D}$ ), in each switching cycle is given by

$$
P_{v D}=\frac{k_{z}}{T_{s D}} B_{m D}^{\beta}\left[t_{o n D}^{1-\alpha}+t_{o f f D}^{1-\alpha}\right]
$$

\section{Switching loss due to transformer self-capacitance}

The capacitive turn-on or switching loss due the selfcapacitance when the converter employs valley switching/boundary conduction mode (BCM) control during charge process is given by [26], [44], [45]

$$
P_{s w C}=\frac{1}{2}\left(n^{2} C_{s}\right)\left(V_{\text {in }}-\frac{V_{\text {out }}}{n}\right)^{2} f_{s w C}
$$

When the output voltage $V_{\text {out }}$ is greater than $n V_{\text {in }}$, the capacitive switching loss $P_{s w C}$ is $0 \mathrm{~W}$, since the converter operates with zero voltage switching (ZVS). The capacitive switching loss due the self-capacitance when the converter employs DCM control during discharge process is [26]

$$
P_{s w D}=\frac{1}{2} C_{s}\left(V_{M s}\right)^{2} f_{s w D}
$$

In DCM, the drain-to-source voltage $V_{M s}$ at the beginning of the next switching cycle can be anywhere between $V_{\text {out }}+\delta_{C} n V_{\text {in }}+\delta_{C} V_{\text {leak } D}$ and $V_{\text {out }}+\left(2 \delta_{C}-1\right) n V_{\text {in }}+\delta_{C} V_{\text {leak } D}$. The expression for $\delta_{c}$ is given by [26]

$$
\delta_{c}=\frac{C_{\text {osss }}}{C_{\text {osss }}+C_{D b}}
$$

The output capacitance $C_{o s s s}$ of $M_{s}$ and junction capacitance $C_{D b}$ of diode $D_{b}$ are approximately $15 \mathrm{pF}$ and $1 \mathrm{pF}$, respectively.

\section{Switching loss due to transformer leakage inductance}

The loss due to the dissipative RCD snubber during charge process is given by

$$
P_{s n C}=\frac{1}{2} L_{l k p} I_{p p k C}^{2} \frac{V_{s n C}}{V_{s n C}-\frac{V_{o u t}}{n}} f_{s w C}
$$

The loss due to the dissipative RCD snubber during discharge process is given by

$$
P_{s n D}=\frac{1}{2} L_{l k s} I_{s p k D}^{2} \frac{V_{s n D}}{V_{s n D}-n V_{i n}} f_{s w D}
$$

where $V_{s n C}$ and $V_{s n D}$ are the snubber clamp voltages for low and high voltage MOSFETs, respectively.

\section{E. Remaining losses in the bidirectional flyback converter}

The remaining losses in the converter during charge process are: switching loss of $M_{p}$, conduction losses of $M_{p}, D_{2}$ and $R_{p s e n s e}$, gate drive loss of $M_{p}$, and power consumption of charge control IC. Similarly, the remaining losses in the converter during discharge process are: switching loss of $M_{s}$, conduction losses of $M_{s}, D_{b}$ and $R_{\text {ssense }}$, gate drive loss of $M_{s}$, and power consumption of discharge control IC. Since during both charge and discharge operations the converter employs BCM and DCM control, respectively, there are no diode reverse recovery losses in both modes. 


\section{EFFICIENCY OPTIMIZATION FOR A DC-DC CONVERTER DRIVING CAPACITIVE LOAD}

Efficient design of a high voltage bidirectional flyback converter, necessitates many trade-offs and iterations with a large number of design variables. The first step of the optimization routine is to determine the design specifications of the converter. The low voltage and high voltage MOSFETs, high voltage diode, turns ratio and magnetizing inductance are used as the constraints in the optimization, and are kept constant throughout the optimization routine. The flow chart of the proposed optimization routine is shown in Fig. 7. The converter specifications are used to calculate the number of primary and secondary turns, for a given ferrite core. The outputs of AWL technique are used to calculate the transformer parasitics. The energy losses during both charge $E_{\text {loss } C}$ and discharge $E_{\text {loss } D}$ modes are calculated and added to represent the total energy loss for that specific core. Finally, the energy efficiencies during charge $\eta_{C}$ and discharge $\eta_{D}$ modes are calculated as a function of output voltage.

The design decisions presented in Table II are used, to limit the solution space of the optimization routine. The ranges for the cores and parameters to be optimized are shown in Table III. The optimization routine iterates through all design possibilities, and finally presents an optimized (most efficient) solution for each core. The outputs of the AWL technique are

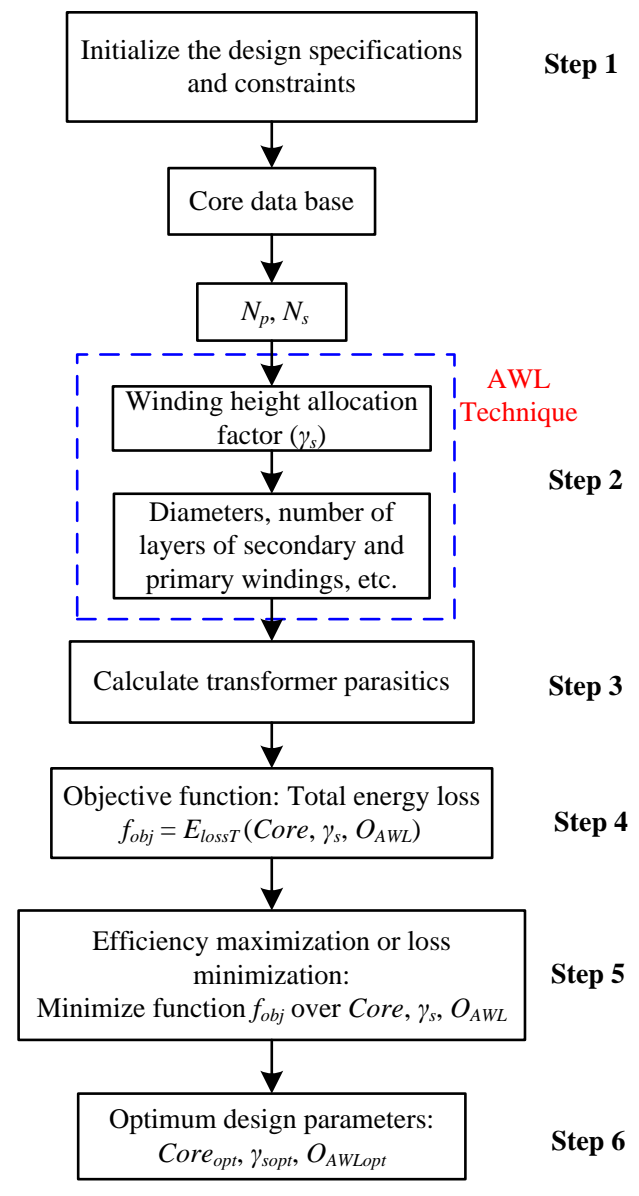

Fig. 7. Flow chart of the proposed efficiency optimization procedure.
TABLE III

RANGES OF THE DESIGN PARAMETERS

\begin{tabular}{c|c}
\hline \hline Parameters & Ranges for optimization \\
\hline \hline & EFD12, EFD 15, EFD 20, \\
EFD 25, E 16, E 20, E 25, E 30, & ETD 29, ETD 34, ETD 39, \\
RM 8, RM 10, RM 12, & PQ 20/20 and PQ 26/20 \\
\hline Height allocation factors for & {$[0.5,0.6,0.7,0.8]$} \\
secondary winding $\left(\gamma_{s}\right)$ & see Section II and Figure 7 \\
\hline Outputs from AWL technique & \\
$O_{A W L}$ & \\
\hline \hline
\end{tabular}

represented as $O_{A W L}$.

The proposed optimization routine is described in the following steps:

1) Transformer turns ratio, peak currents (for charge and discharge operations), magnetizing inductance are selected from the design specifications and constraints. Number of primary and secondary turns are calculated for a given transformer core.

2) The proposed AWL technique is applied to calculate an array of the outputs (diameter, number of layers, turns per layer, number of parallel wires, for both primary and secondary windings). The condition for the last layer fill factor is $F F_{L L}>0.85$, this is to approximately make, equal number of turns per layer on final secondary layer and remaining secondary layers).

3) The transformer parasitics are calculated for each set of outputs resulted from AWL technique.

4) The objective function $f_{o b j}$ is defined as the sum of the total energy losses in the bidirectional flyback converter over a set of operating points, and is given by

$$
f_{o b j}=E_{\text {loss }}\left(\text { Core, } \gamma_{s}, O_{A W L}\right)
$$

5) The efficiency optimization or loss minimization of function $f_{o b j}$ is

$$
\begin{gathered}
\min _{\text {Core, } \gamma_{s}, O_{A W L}}\left[f_{\text {obj }}\right]=\min _{\min _{\text {Core, } \gamma_{s}, O_{\text {AWL }}, \gamma_{s}, O_{A W L}}\left[E_{\text {loss } T}\right]=}\left[E_{\text {loss }}+E_{\text {loss }}\right]
\end{gathered}
$$

6) The end results of the optimization routine are the set of parameters which contributes to the minimum total energy loss. Finally, the optimum charge and discharge energy efficiencies are calculated as a function of output voltage

$$
\eta_{C}\left(V_{\text {out }}\right)=\frac{E_{\text {load }}\left(V_{\text {out }}\right)}{E_{\text {load }}\left(V_{\text {out }}\right)+E_{\text {loss } C}}=\frac{0.5 C_{\text {load }} V_{\text {out }}^{2}}{0.5 C_{\text {load }} V_{\text {out }}^{2}+E_{\text {loss } C}}
$$

$$
\eta_{D}\left(V_{\text {out }}\right)=\frac{E_{\text {load }}\left(V_{\text {out }}\right)-E_{\text {loss } D}}{E_{\text {load }}\left(V_{\text {out }}\right)}=\frac{0.5 C_{\text {load }} V_{\text {out }}^{2}-E_{\text {loss } D}}{0.5 C_{\text {load }} V_{\text {out }}^{2}}
$$

\section{EFFICIENCY OPTIMIZATION RESULTS AND EXPERIMENTAL VALIDATION}

\section{A. Details of the optimization results:}

The components used in the bidirectional flyback converter except the transformer are shown in Table IV. All losses in the bidirectional flyback converter are calculated in MATLAB 
TPEL-Reg-2014-09-1319

TABLE IV

COMPONENTS USED IN THE BIDIRECTIONAL FLYBACK CONVERTER

\begin{tabular}{|c|c|}
\hline Component & Name / Manufacturer \\
\hline Low voltage MOSFET $M_{p}$ & $\begin{array}{c}\text { IPB600N25N3 G } \\
{[250 \mathrm{~V}, 25 \mathrm{~A}, 60 \mathrm{~m} \Omega]}\end{array}$ \\
\hline High voltage MOSFET $M_{s}$ & $\begin{array}{c}\text { IXTV03N400S } \\
{[4 \mathrm{kV}, 300 \mathrm{~mA}, 290 \Omega]}\end{array}$ \\
\hline $\begin{array}{c}\text { High voltage diode } D_{2} \text { or } \\
D_{b}\end{array}$ & $\begin{array}{c}\text { SP5LFG } \\
{\left[5 \mathrm{kV}, 400 \mathrm{~mA}, 50 \mathrm{~ns}\left(t_{r r}\right)\right]}\end{array}$ \\
\hline Film capacitive load $C_{\text {load }}$ & WIMA [400 nF, $3 \mathrm{kV}]$ \\
\hline Analog control IC & LT3751 \\
\hline
\end{tabular}

using the proposed comprehensive loss model. The winding loss is calculated during both charge and discharge processes, up to $100^{\text {th }}$ order harmonics $\left(N_{h}=100\right)$. The optimum secondary height allocation factor $\gamma_{s}$, for each core is provided in Fig. 8. Figure 9 provides the results of the optimum charge, discharge and overall (product of charge and discharge) energy efficiencies, and an overall energy efficiency of a typical design where 50\% space is allocated for primary and secondary windings, at an output voltage of $2.5 \mathrm{kV}$, with respect to different core volumes.

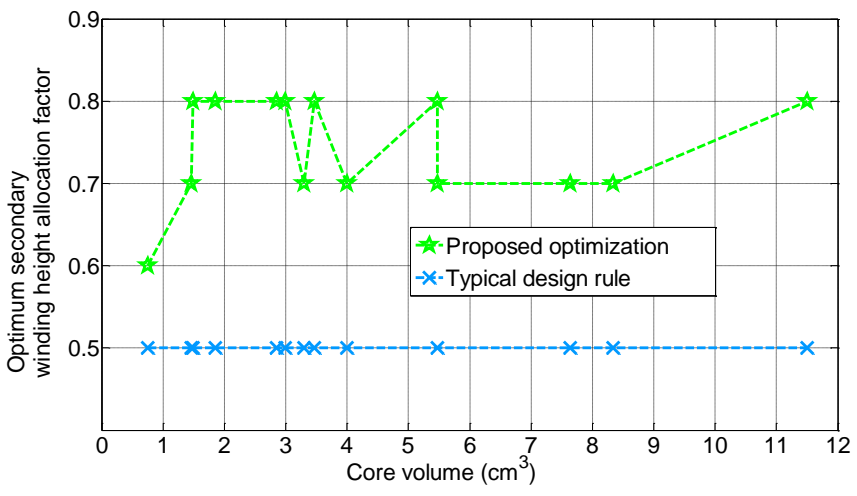

Fig. 8. Optimum secondary winding height allocation factor $\gamma_{s}$ vs. core volume.

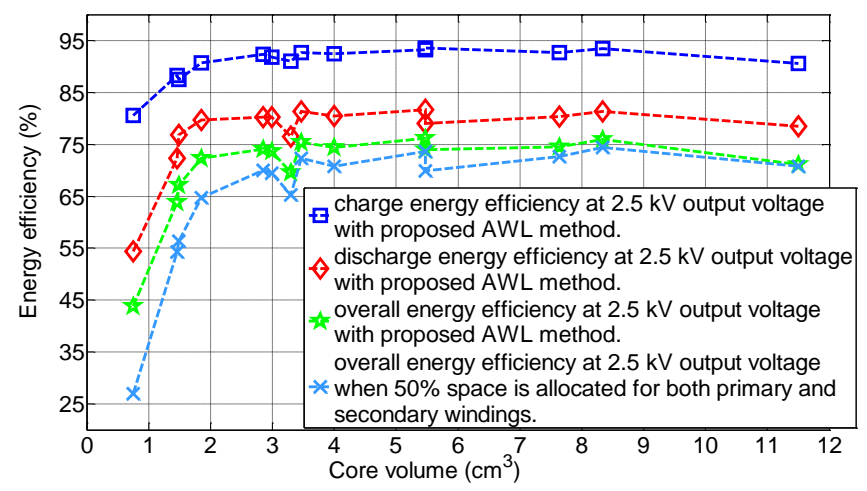

Fig. 9. Calculated optimized energy efficiencies at an output voltage of 2.5 $\mathrm{kV}$ vs. core volume. The sequence of the 14 cores is:

[E 16, EFD 20, E 20, RM 8, PQ 20/20, E 25, EFD 25, RM 10, E 30, PQ 26/20, ETD 29, ETD 34, RM 12, ETD 39].

The total energy loss $E_{\text {loss }}$ at an output voltage of $2.5 \mathrm{kV}$ is the loss occurred in all components of the converter, for charging the capacitive load from $0 \mathrm{~V}$ to $2.5 \mathrm{kV}$. Similarly, the total energy loss $E_{\text {loss }}$ at an output voltage of $2.5 \mathrm{kV}$ is the loss occurred in all components of the converter, for discharging the capacitive load from $2.5 \mathrm{kV}$ to $0 \mathrm{~V}$. The most efficient and smallest transformer (or core) designs are two important outcomes of the proposed efficiency optimization routine. Table V shows a comparison of smallest core (SCD) and optimized core (OCD) designs.

The smallest and optimized core designs are described below: 1) Smallest core design ( $S C D)$

The smallest core is selected as the core whose temperature rise is less than the maximum temperature limit $\left(130{ }^{\circ} \mathrm{C}\right)$. Several small cores such as, EFD 12, EFD 15, E 16 have been used in the optimization routine, out of those E 16 is the smallest core with a maximum temperature rise of $94{ }^{\circ} \mathrm{C}$ (in a single bidirectional charge and discharge cycle). In the optimization routine, for all small cores (EFD 12, EFD 15, E 16), a maximum flux density of $0.33 \mathrm{~T}$ is chosen, hence for $\mathrm{E}$ 16, $N_{p}$ becomes 29. As shown in Fig. 8, the optimum secondary height allocation factor for E 16 core is 0.6 , this is for accommodating the 29 primary turns on the small core. The spacing between the secondary winding layers for SCD is $66 \mu \mathrm{m}$.

\section{2) Optimized core design (OCD)}

The core, which has a lower volume and a better overall energy efficiency compared with other cores, is selected as an optimized core. In Fig. 9, most of the cores whose volumes are above $2.85 \mathrm{~cm}^{3}$ have an overall energy efficiency between $74 \%$ and $76 \%$. The EFD 25 core with volume $3.3 \mathrm{~cm}^{3}$ has a lower discharge efficiency (hence lower overall efficiency), since its window height $H_{W}$ has been less compared with the neighboring cores, such as the EF 25 and RM 10 (see Fig. 9). For a better trade-off between the core volume and overall efficiency, the cores whose volume is between 2.85 and $4 \mathrm{~cm}^{3}$ could be more suitable for the high voltage driver (with specifications shown in Table I). The cores with volumes 4 $\mathrm{cm}^{3}$ (E 30) and $2.85 \mathrm{~cm}^{3}$ (PQ 20/20) have overall efficiencies of $75 \%$ and $74 \%$, respectively. However, PQ $20 / 20$ core is selected as an optimized core, as a $40 \%$ increase in the core volume provides only $1 \%$ increase in the overall energy efficiency. In the optimization routine, a maximum flux density of $0.26 \mathrm{~T}$ is chosen for all cores whose volumes are greater than equal to $1.46 \mathrm{~cm}^{3}$ (EFD 20). As shown in Fig. 8, for all cores except the smallest core, the optimum secondary winding height allocation factor varies between 0.7 and 0.8 . For PQ 20/20 core, the secondary height allocation factor is 0.8 . The spacing between the secondary winding layers for OCD is $0.9 \mathrm{~mm}$.

The energy loss distributions for PQ 20/20 core during charge and discharge processes are shown in Figs. 10(a) and 10(b), respectively. During charge process, the converter operates with boundary conduction mode (BCM) control; hence the capacitive switching loss due to the self-capacitance is very low compared with other losses. The significant losses during charge process are: switching loss of low voltage MOSFET $M_{p}$, switching loss/snubber loss due to the transformer leakage inductance and transformer winding loss. During discharge process, the converter operates with discontinuous conduction mode (DCM) control; hence the capacitive switching loss due to the self-capacitance cannot be 
This article has been accepted for publication in a future issue of this journal, but has not been fully edited. Content may change prior to final publication. Citation information: DOI 10.1109/TPEL.2014.2379439, IEEE Transactions on Power Electronics

TPEL-Reg-2014-09-1319

TABLE V

RESUlts OF THE OPTIMIZATION FOR SMALLEST CORE DESIGN (SCD) AND OPTIMIZED CORE DESIGN (OCD)

\begin{tabular}{|c|c|c|}
\hline Parameter & 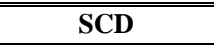 & 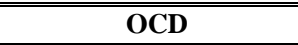 \\
\hline Core name & E 16 & PQ 20/20 \\
\hline Core volume & $0.75 \mathrm{~cm}^{3}$ & $2.85 \mathrm{~cm}^{3}$ \\
\hline Maximum flux density $B_{m C}$ & $0.33 \mathrm{~T}$ & $0.26 \mathrm{~T}$ \\
\hline Total number of turns of primary $N_{p} /$ secondary $N_{s}$ winding & $29 / 720$ & $12 / 300$ \\
\hline Number of layers of primary $n_{l p} /$ secondary $n_{l s}$ & $2 / 8$ & $1 / 4$ \\
\hline Number of parallel wires (or squares) of primary $n_{\text {parp }} /$ secondary $n_{\text {pars }}$ & $1 / 1$ & $1 / 1$ \\
\hline Number of turns (or squares) per layer of primary / secondary & $15 / 90$ & $12 / 75$ \\
\hline Diameter of primary $d_{p} /$ secondary winding $d_{s}$ & $0.4 \mathrm{~mm} / 0.1 \mathrm{~mm}$ & $(0.5+0.2) \mathrm{mm} / 0.143 \mathrm{~mm}$ \\
\hline Primary magnetizing inductance $L_{m p}$ & $40 \mu \mathrm{H}$ & $44 \mu \mathrm{H}$ \\
\hline Height allocation for secondary winding $\gamma_{s}$ & 0.6 & 0.8 \\
\hline Spacing (or insulation) between secondary layers $d_{\text {insulation }}$ & $66 \mu \mathrm{m}$ & $0.9 \mathrm{~mm}$ \\
\hline $\begin{array}{l}\text { Transformer maximum temperature rise in a single bidirectional charge and } \\
\text { discharge cycle }\end{array}$ & $94^{\circ} \mathrm{C}$ & $30^{\circ} \mathrm{C}$ \\
\hline
\end{tabular}

neglected. The significant losses during discharge process are: switching loss of high voltage MOSFET $M_{s}$, switching loss due to the transformer leakage inductance, and capacitive switching loss due to the transformer self-capacitance.
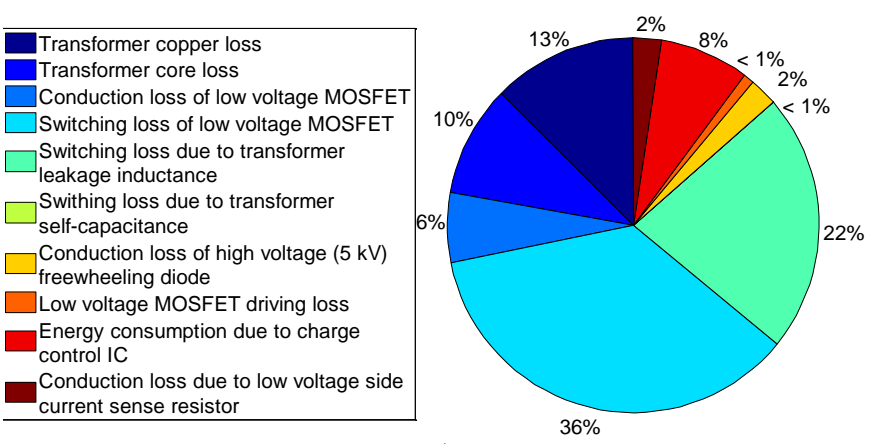

a)

\begin{tabular}{|l|}
\hline Transformer copper loss \\
Transformer core loss \\
Conduction loss of high voltage \\
(4 kV) MOSFET \\
Switching loss of high voltage \\
(4 kV) MOSFET \\
Switching loss due to transformer \\
leakage inductance \\
Switching loss due to transformer \\
self-capacitance \\
Conduction loss of high voltage ( $5 \mathrm{kV})$ \\
blocking diode \\
High voltage (4 kV) MOSFETdriving loss \\
Energy consumption due to discharge \\
control IC \\
Conduction loss of body diode of \\
low voltage MOSFET
\end{tabular}

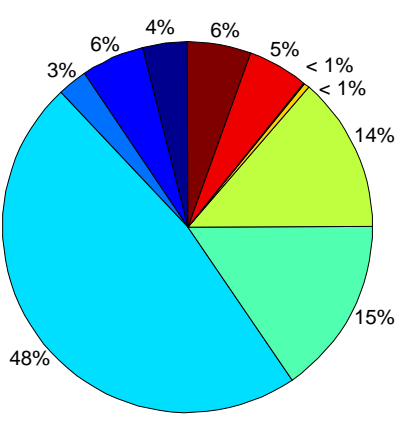

b)

Fig. 10. Energy loss distribution of the optimized core (PQ 20/20), a) during charge and $b$ ) during discharge process.

\section{B. Experimental Results}

The experimental prototype of the bidirectional flyback converter is shown in Fig. 11(a). The prototypes of optimized and smallest transformers are shown in Fig. 11(b). The comparison of measured [19] and calculated charge and discharge energy efficiencies for the smallest and optimized cores is provided in Figs. 12(a) and 12(b), respectively. In Figs. 12(a) and 12(b), the maximum difference between the calculated and measured energy efficiencies during charge and discharge modes is less than $\pm 5 \%$, except for the smallest core

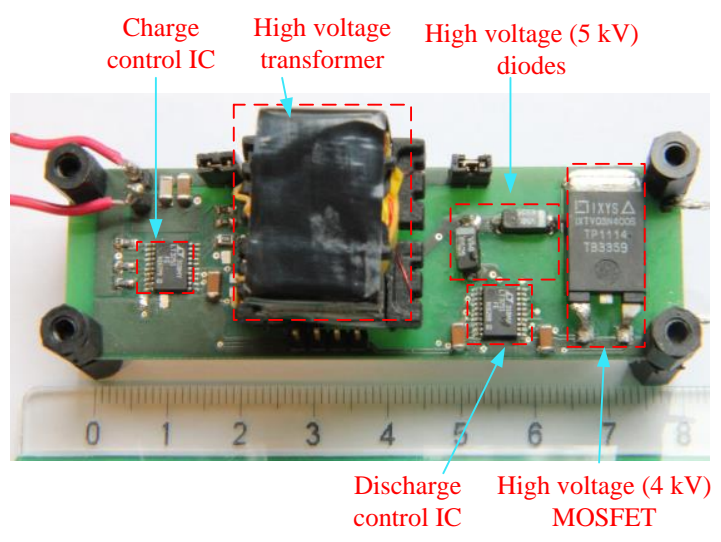

a)

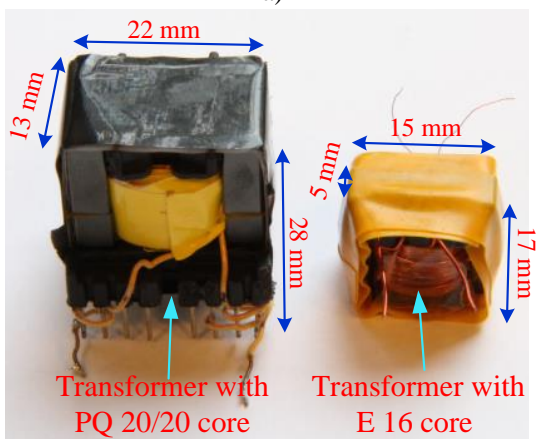

b)

Fig. 11. a) Experimental prototype of the bidirectional flyback converter with PQ 20/20 core; b) Optimized (PQ 20/20) and smallest (E 16) transformers.

design at very high output voltage $(>2.2 \mathrm{kV})$. The total loss due to the transformer parasitics for SCD is higher than that of OCD by 5 times, and the remaining losses in the converter, are the same for both designs.

In the bidirectional flyback converter an input capacitance $C_{\text {in }}$ of $1800 \mu \mathrm{F}(100 \mathrm{~V})$ is used. The primary $R_{\text {psense }}$ and secondary $R_{\text {ssense }}$ sense resistors used in the converter are 25 $\mathrm{m} \Omega$ and $0.5 \Omega$, respectively. The Z-type winding scheme [25] is implemented in the secondary winding of the flyback transformer, to reduce the self-capacitance. To remove the interlayer insulation tape between primary and secondary windings, triple insulated wire (TEX-E) from Furukawa [46] 


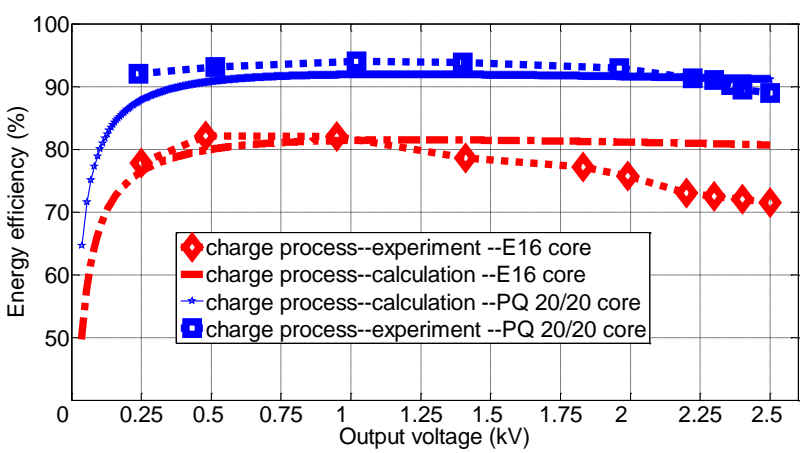

a)

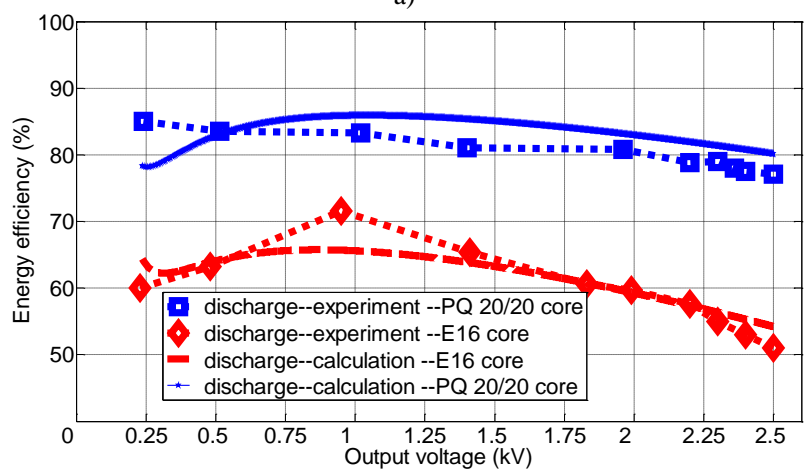

b)

Fig. 12. Comparison of calculated and measured a) charge and b) discharge energy efficiencies for the optimized (PQ 20/20) and smallest (E 16) cores.

is used for the primary winding, and it has an insulation thickness of $0.2 \mathrm{~mm}$. As shown in Table VI, $0.7 \mathrm{~mm}$ overall diameter wire $(0.5 \mathrm{~mm}$ TEX-E wire) is used in the primary winding of PQ 20/20 core, and $0.4 \mathrm{~mm}$ overall diameter normal single insulated wire is used in the primary winding of E 16 core, due to non-availability of $0.2 \mathrm{~mm}$ TEX-E wire during practical implementation.

For PQ 20/20 core, no snubber is used in either low voltage or high voltage side. Since the leakage inductance of E 16 core is very high, RCD snubbers are used in both primary and secondary sides and the loss model is updated accordingly. The loss model automatically considers RCD snubbers, when the leakage inductance $L_{l k p}$ in the optimization is higher than $1.2 \mu \mathrm{H}$. The low voltage $V_{s n C}$ and high voltage $V_{s n D} \mathrm{RCD}$ snubber clamp voltages are chosen as $\frac{2 V_{\text {out } \max }}{n}$ and $2 n V_{\text {in }}$, respectively, with a maximum output voltage $V_{\text {out } \max }$ of 2.5 $\mathrm{kV}$. The insulation between the secondary layers of transformer is provided by the Kapton tape which has a single layer thickness of $66 \mu \mathrm{m}$. The calculated and measured transformer parasitics for both SCD and OCD are provided in Table VI. The comparison shows that the model used for calculating the parasitics, for multiple solutions in the optimization routine is accurate enough.

\section{CONCLUSIONS}

This paper presents an efficiency optimization approach for a high voltage bidirectional flyback dc-dc converter. The energy efficiency is optimized using a proposed new automatic winding layout generator technique and a
TABLE VI

COMPARISON OF CALCULATED AND MEASURED TRANSFORMER PARAMETERS FOR SMALLEST AND OPTIMIZED CORE DESIGNS

\begin{tabular}{|c|c|c|c|c|}
\hline \multirow[b]{2}{*}{$\begin{array}{l}\text { Parameter of } \\
\text { Transformer }\end{array}$} & \multicolumn{2}{|c|}{ 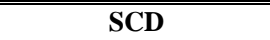 } & \multicolumn{2}{|c|}{ 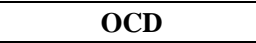 } \\
\hline & $\begin{array}{c}\text { Calculati } \\
\text { on }\end{array}$ & $\begin{array}{c}\text { Measure } \\
\text { ment }\end{array}$ & $\begin{array}{c}\text { Calculati } \\
\text { on }\end{array}$ & $\begin{array}{c}\text { Measur } \\
\text { ement }\end{array}$ \\
\hline $\begin{array}{l}\text { Leakage inductance } \\
\text { referred to primary } \\
L_{l k p} \\
\end{array}$ & $3.22 \mu \mathrm{H}$ & $3.3 \mu \mathrm{H}$ & $818 \mathrm{nH}$ & $857 \mathrm{nH}$ \\
\hline $\begin{array}{l}\text { Self-capacitance of } \\
\text { secondary (high } \\
\text { voltage) winding } C_{s}\end{array}$ & $18.1 \mathrm{pF}$ & $21.62 \mathrm{pF}$ & $4.5 \mathrm{pF}$ & $6.23 \mathrm{pF}$ \\
\hline $\begin{array}{c}\text { Dc resistance of } \\
\text { secondary (high } \\
\text { voltage) winding } R_{s}\end{array}$ & $46.54 \Omega$ & $44 \Omega$ & $15.3 \Omega$ & $18.2 \Omega$ \\
\hline
\end{tabular}

comprehensive loss model. The proposed optimization technique is experimentally validated on a $25 \mathrm{~W}$ (charging power) high voltage bidirectional flyback converter. The measured charge and discharge energy efficiencies of the converter, with PQ 20/20 core at an output voltage of $2.5 \mathrm{kV}$ are $89 \%$ and $77.1 \%$, respectively. For both optimized and smallest core designs, energy efficiency during discharge process is less compared to that during charge process, mostly due to the switching loss of the output capacitance of high voltage MOSFET.

The important conclusions of this paper are as follows:

1) The proposed AWL technique is highly recommended for high input or high output voltage applications which need a transformer with many turns (primary or secondary). It automatically calculates and provides the necessary winding design data such as wire sizes, number of winding layers, number of turns per layer, and the number of parallel wires.

2) The AWL technique can be easily extended to interleaved and/or sectioned transformer structures.

3) Transformer parasitics are calculated for each set of outputs from AWL technique, which are needed to estimate the energy efficiency. By iteratively changing the spacing between secondary winding layers, the loss due to self-capacitance, leakage inductance and dc resistance of the transformer are balanced.

4) Providing a very thick insulating tape between the secondary winding layers reduces the self-capacitance. The self-capacitance can be reduced significantly by allocating more space (or height) for the secondary winding.

5) Non-sectioned bobbins with larger window height are suitable for minimizing the self-capacitance, hence are recommended for high voltage capacitor charge and discharge application.

6) The output of the proposed efficiency optimization (overall energy efficiency vs. core volume curve) gives the flexibility for the designer to choose the necessary core and winding configurations.

\section{REFERENCES}

[1] Y. Bar-Cohen, Electroactive Polymer [EAP] Actuators as Artificial Muscles: Reality, Potential, and Challenges, $2^{\text {nd }}$ Ed. Washington, DC: SPIE, 2004. 
[2] R. E. Pelrine, R. D. Kornbluh, Q. Pei, J. P. Joseph, "High-speed electrically actuated elastomers with strain greater than $100 \%$," Science, vol. 287, pp. 836-839, 2000.

[3] F. Carpi, D. DE Rossi, R. Kornbluh, R. Pelrine, P. Sommer-Larsen, Eds, "Dielectric Elastomer As Electromechanical Transducers," Amsterdam, The Netherlands: Elsevier, 2008.

[4] Danfoss PolyPower, Denmark, Online avilable: http://www.polypower.com/ [accessed 16 Oct. 2014].

[5] M. Tryson, H. E. Kiil, M. Benslimane, "Powerful tubular core free dielectric electro active polymer (DEAP) push actuator," in Proc. SPIE, vol. 7287, 2009.

[6] R. Sarban, B. Lassen, M. Willatzen, "Dynamic Electromechanical Modeling of Dielectric Elastomer Actuators With Metallic Electrodes," IEEE/ASME Tran. Mechatronics, vol. 17, no. 5, pp. 960967, Oct. 2012.

[7] P. Thummala, H. Schneider, Z. Zhang, M. A. E. Andersen, R. Sarban, "A new Incremental Actuator based on Electro Active Polymer: Conceptual, Control and Driver Design Considerations," IEEE/ASME Trans. Mechatronics (under review process).

[8] P. Thummala, Z. Zhang, M. A. E. Andersen, S. Rahimullah, "Dielectric electro active polymer incremental actuator driven by multiple highvoltage bi-directional DC-DC converters," in Proc. IEEE ECCE USA, pp. 3837-3844, 2013.

[9] R. W. Erickson, D. Maksimovic, Fundamentals of Power Electronics, $2^{\text {nd }}$ Ed., New York: Springer, 2001.

[10] J. Elmes, C. Jourdan, O. Abdel-Rahman, I. Batarseh, "High-Voltage, High-Power-Density DC-DC Converter for Capacitor Charging Applications," in Proc. IEEE APEC, pp. 433-439, 2009.

[11] T. Andersen, M. S. Rødgaard, O. C. Thomsen, M. A. E. Andersen, "Low voltage driven dielectric electro active polymer actuator with integrated piezoelectric transformer based driver," in Proc. SPIE, vol. 7976, p. $79762 \mathrm{~N}, 2011$.

[12] S. K. Chung, H. B. Shin, "High-voltage power supply for semi-active suspension system with ER-fluid damper," IEEE Trans. Vehicular Technology, vol. 53, no. 1, pp. 206- 214, Jan. 2004.

[13] L. Eitzen, T Hoffstadt, J. Maas, "Power electronics concepts for driving EAP actuators," in Proc. SPIE, Electroactive Polymer Actuators and Devices (EAPAD), pp. 86870D, 2013.

[14] K. Venkatesan, "Current Mode Controlled Bidirectional Flyback Converter," in Proc. IEEE PESC, pp. 835-842, 1989.

[15] G. Chen, Y.-S. Lee, S.Y.R. Hui, D. Xu, Y. Wang, "Actively clamped bidirectional flyback converter," IEEE Trans. on Industrial Electronics, vol. 47, no. 4, pp. 770-779, Aug. 2000.

[16] T. Bhattacharya, V. S. Giri, K. Mathew, L. Umanand, "Multiphase Bidirectional Flyback Converter Topology for Hybrid Electric Vehicles," IEEE Trans. Industrial Electronics, vol. 56, no. 1, pp. 78-84, Jan. 2009.

[17] M. Karpelson, G. Y. Wei, R. J. Wood, "Driving high voltage piezoelectric actuators in microrobotic applications," Sensors and Actuators A, vol. 176, pp. 78- 89, 2012.

[18] F. Zhang, Y. Yan, "Novel Forward-Flyback Hybrid Bidirectional DCDC Converter," IEEE Trans. Industrial Electronics, vol. 56, no. 5, pp. 1578-1584, May 2009.

[19] P. Thummala, Z. Zhang, M. A. E. Andersen, "High Voltage Bidirectional Flyback Converter for Capacitive Actuator", in Proc. IEEE EPE, pp. 1-10, 2013.

[20] P. Thummala, H. Schneider, Z. Ouyang, Z. Zhang, M. A. E. Andersen, "Estimation of transformer parameters and loss analysis for high voltage capacitor charging application," in Proc. IEEE ECCE Asia, pp. 704-710, 2013.

[21] C. W. T. McLyman, Transformer and Inductor Design Handbook, $3^{\text {rd }}$ Ed., New York: Marcel Dekker, 2004.

[22] W. G. Hurley, W. H. Wolfle, Transformers and Inductors for Power Electronics: Theory, Design and Applications, $1^{\text {st }}$ Ed., John Wiley and Sons Ltd., 2013.

[23] M. Kazimierczuk, High-frequency magnetic components, $2^{\text {nd }}$ Ed., John Wiley and Sons Ltd., 2014.

[24] P. Thummala, H. Schneider, Z. Zhang, A. Knott, M. A. E. Andersen, "Optimization of a bi-directional flyback converter for a high voltage capacitor charging application," in Proc. IEEE APEC, pp. 2556-2563, 2014.

[25] H. Schneider, P. Thummala, L. Huang, A. Knott, Z. Zhang, M. A. E. Andersen, "Investigation of Transformer Winding Architectures for High Voltage Capacitor Charging Applications," in Proc. IEEE APEC, pp. 334-341, 2014.
[26] P. Thummala, D. Maksimovic, Z. Zhang, M. A. E. Andersen, "Digital control of a high-voltage $(2.5 \mathrm{kV})$ bidirectional DC-DC converter for driving a dielectric electro active polymer (DEAP) based capacitive actuator," in Proc. IEEE ECCE USA, 14-18 $8^{\text {th }}$ Sept. 2014.

[27] N. O. Sokal, R. Redl, "Control algorithms and circuit designs for optimal flyback-charging of an energy storage capacitor (e.g., for flash lamp or defibrillator)," IEEE Trans. Power Electronics, vol. 12, no. 5, pp. 885-894, Sep. 1997.

[28] R. Prieto, J.A. Cobos, O. Garcia, R. Asensi, J. Uceda, "Optimizing the winding strategy of the transformer in a flyback converter," in Proc. IEEE PESC, pp. 1456-1462, 1996.

[29] C. R. Sullivan, T. Abdallah, T. Fujiwara, "Optimization of a flyback transformer winding considering two-dimensional field effects, cost and loss," in Proc. IEEE APEC, pp.116-122, 2001.

[30] H. K. Sang, D. Maksimovic, I. Cohen, "Efficiency Optimization in Digitally Controlled Flyback DC-DC Converters Over Wide Ranges of Operating Conditions," IEEE Trans. Power Electronics, vol. 27, no. 8, pp. 3734-3748, Aug. 2012.

[31] A. C. Nanakos, E.C. Tatakis, N. P Papanikolaou, "A WeightedEfficiency-Oriented Design Methodology of Flyback Inverter for AC Photovoltaic Modules," IEEE Trans. Power Electronics, vol. 27, no. 7, pp. 3221-3233, July 2012.

[32] X. Zhou, T. G. Wang, F. C. Lee, "Optimizing Design for Low Voltage DC-DC Converters," in Proc. IEEE APEC, pp. 612-616, 2007.

[33] U. Badstuebner, J. Biela, J. W. Kolar, "An optimized, $99 \%$ efficient, 5 $\mathrm{kW}$, phase-shift PWM DC-DC converter for data centers and telecom applications," in Proc. IEEE IPEC, pp.626,634, 21-24 June 2010.

[34] J. Biela, U. Badstuebner, J. W. Kolar, "Impact of Power Density Maximization on Efficiency of DC-DC Converter Systems," IEEE Trans. Power Electronics, vol. 24, no. 1, pp. 288-300, Jan 2009.

[35] E. C. Snelling, Soft Ferrites-Properties and applications, $2^{\text {nd }}$ Ed. London, UK, Butterworth, 1988.

[36] L. Dalessandro, F. da Silveira Cavalcante, J. W. Kolar, "SelfCapacitance of High-Voltage Transformers," IEEE Trans. Power Electronics, vol. 22, no.5, pp. 2081-2092, Sept. 2007.

[37] J. Biela, J. W. Kolar, "Using Transformer Parasitics for Resonant Converters-A Review of the Calculation of the Stray Capacitance of Transformers," IEEE Trans. Industry Applications, vol. 44, no.1, pp. 223-233, 2008.

[38] W.G. Hurley, E. Gath, J. G. Breslin, "Optimizing the AC resistance of multilayer transformer windings with arbitrary current waveforms," IEEE Trans. Power Electronics, vol. 15, no. 2, pp. 369376, Mar 2000.

[39] J. A. Ferreira, "Improved analytical modeling of conductive losses in magnetic components," IEEE Trans. Power Electronics, vol. 9, no. 1, pp. 127,131, Jan 1994.

[40] J. Vandelac, P. D. Ziogas, "A Novel Approach for Minimizing HighFrequency Transformer Copper Losses," IEEE Trans. Power Electronics, vol. 3, no. 3, pp. 266-277, Jul. 1988.

[41] S. H. Kang, "Efficiency Optimization in Digitally Controlled Flyback DC-DC Converters Over Wide Ranges of Operating Conditions," Ph.D. Thesis, Dept. Electrical, Computer and Energy Engineering, University of Colorado Boulder, USA 2011.

[42] LT3751 datasheet, "High voltage capacitor charger controller with regulation," Linear Technology Corporation, USA, Online available: http://cds.linear.com/docs/en/datasheet/3751fc.pdf [accessed 16 Oct. 2014].

[43] K. Venkatachalam, C. R. Sullivan, T. Abdallah, H. Tacca, "Accurate prediction of ferrite cores loss with nonsinusoidal waveforms using only Steinmetz parameters," in Proc. IEEE Workshop Comput. Power Electron., pp. 36-41, 2002.

[44] M. T. Zhang, M. M. Jovanovic, F. C. Lee, "Design considerations and performance evaluations of synchronous rectification in flyback converters," in Proc. IEEE APEC, pp. 623-630, Feb 1997.

[45] C. P. Basso, Switch-mode power supplies-spice simulations and practical designs, $2^{\text {nd }}$ Ed., McGraw Hill, 2008.

[46] Furukawa webpage, "Triple Insulated Wire: Standard Type TEX-E," Furukawa Electric, Japan, Online available: http://www.furukawa.co.jp/makisen/eng/product/texe series.htm [accessed 16 Oct. 2014]. 


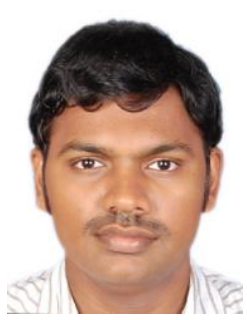

Prasanth Thummala (S'11) was born in India in 1987. He received the B.Tech. degree in electrical and electronics engineering from Acharya Nagarjuna University, Guntur, India, in 2008, and the M.Tech degree in control systems engineering, at the department of electrical engineering, from the Indian Institute of Technology Kharagpur, Kharagpur, India, in 2010. He was a Ph.D. student in the electronics group, department of electrical engineering, Technical University of Denmark (DTU), Denmark, from Nov. 2011 to Nov. 2014.

From Sept. 2013 to Jan. 2014, he was a Visiting PhD student in Colorado Power Electronics Center (CoPEC), at the University of Colorado Boulder, Boulder, CO, USA. He received the first prize UTRC best student paper award at the IEEE ECCE USA conference held in Denver, CO, USA, 2013. His research interests include modeling and control of power electronic converters, high-voltage switch-mode power converters for driving capacitive loads, magnetic design, digital control and system identification.

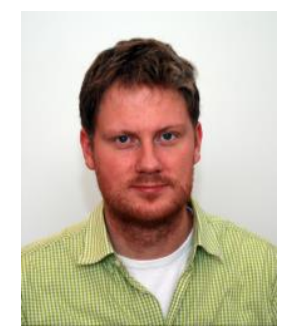

Henrik Schneider (S'11) was born in Denmark and received a master's degree in electrical engineering from the Technical University of Denmark in 2009. The following two years he worked as an R\&D engineer within power electronics.

In 2011 he was enrolled as a Ph.D. at the Technical University of Denmark with a focus on switch mode power supplies and audio amplifiers. He received the best paper award at the IEEE ECCE Asia conference held in Melbourne, Australia, 2013 and a best presentation award at the IEEE APEC conference in Dallas, USA, 2014. His research interests include, efficiency and power density optimization of power electronics, audio system integration, magnetic design and finite element modeling.

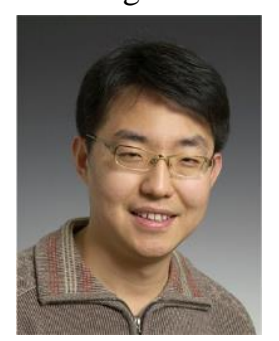

Zhe Zhang (S'07, M'11) received the B.Sc. and M.Sc. degrees in power electronics from Yanshan University, Qinhuangdao, China, in 2002 and 2005, respectively, and the Ph.D. degree from the Technical University of Denmark, Kgs. Lyngby, Denmark, in 2010.

$\mathrm{He}$ is currently an Associate Professor with the Department of Electrical Engineering, at the Technical University of Denmark. From 2005 to 2007, he was an Assistant Professor with Yanshan University. From June 2010 to August 2010, he was with the University of California, Irvine, CA, USA, as a visiting scholar. He was a Postdoctoral Researcher and Assistant Professor at the Technical University of Denmark between 2011 and 2014. He has authored or co-authored more than 70 transactions and conference papers. His current research interests include DC/DC converters, multiple-input converters, and multi-level inverters for renewable energy systems (RES), hybrid electric vehicles (HEV) and uninterruptable power supplies (UPS).

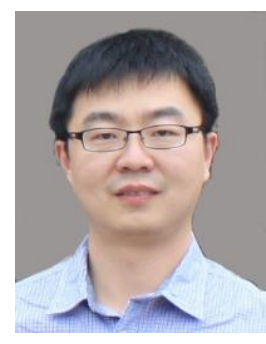

Ziwei Ouyang (S'07, M'11) received the B.S degree in electrical engineering from the Naval University of Engineering, Wuhan, China, in 2004, the M.S degree from the Tianjin University of Technology, Tianjin, China, in 2007, and the Ph.D. degree from the Technical University of Denmark (DTU), Denmark, in 2011. He worked as a Postdoctoral Researcher at DTU from 2011 to 2013 and is currently assistant professor in the Department of Electrical Engineering at DTU.

His current research interests include advanced magnetics design, modeling and integration in switch mode power supplies, dc/dc converters, and digital control in high-power reversible converters. He has over 30 peer-reviewed journal and conference publications and currently he is the holder of three US/EP/PCT patents. He received the Young Engineer Award at PCIM Asia 2014 and Best Paper Awards in ECCEAsia conferences in 2010 and 2012, respectively. He is a member of the IEEE PELS, IES and Magnetics societies.

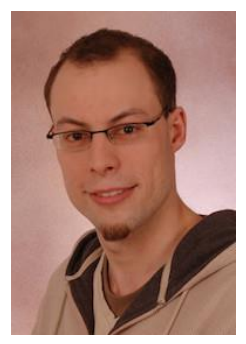

Arnold Knott (M'10) received the DiplomIngenieur $(\mathrm{FH})$ degree from the University of Applied Sciences in Deggendorf, Germany, in 2004. From 2004 until 2009 he has been working with Harman/Becker Automotive Systems GmbH in Germany and USA, designing switch-mode audio power amplifiers and power supplies for automotive applications.

In 2010 he earned the Ph.D. degree from the Technical University of Denmark, Kongens Lyngby, Denmark working on a research project under the title "Improvement of out-ofband Behaviour in Switch-Mode Amplifiers and Power Supplies by their Modulation Topology". From 2010 to 2013 he was Assistant Professor and since 2013 Associate Professor at the Technical University of Denmark. His interests include switch-mode audio power amplifiers, power supplies, active and passive components, integrated circuit design, acoustics, radio frequency electronics, electromagnetic compatibility and communication systems.

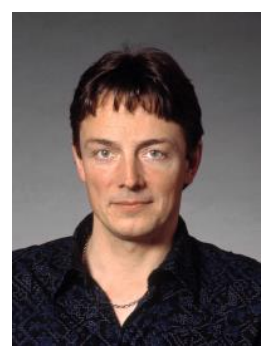

Michael A. E. Andersen (M'88) received the M.Sc.E.E. and Ph.D. degrees in power electronics from the Technical University of Denmark, Kgs. Lyngby, Denmark, in 1987 and 1990, respectively. $\mathrm{He}$ is currently a Professor in power electronics and head of the Electronics group at the Technical University of Denmark (DTU). Since 2009 he has been the Deputy Head of the Department at the Department of Electrical Engineering, Technical University of Denmark.

He received the best poster prize in UPEC 1991 conference. He has authored and co-authored more than 280 publications. From 2010, he is serving as an Associate Editor of IEEE Transactions on Power Electronics. His research areas include switch mode power supplies, piezoelectric transformers, power factor correction, and switch mode audio power amplifiers. 